\title{
Atuação profissional no âmbito da segurança alimentar e nutricional na perspectiva de coordenadores de cursos de graduação em Nutrição
}

\author{
Viviane Laudelino Vieira ${ }^{1}$ \\ Natália Utikava ${ }^{2}$ \\ Ana Maria Cervato-Mancuso ${ }^{3}$
}

VIEIRA, V.L.; UTIKAVA, N.; CERVATO-MANCUSO, A.M. Professional practice relating to food and nutritional security from the perspective of coordinators of undergraduate nutrition courses. Interface - Comunic., Saude, Educ., v.17, n.44, p.157-70, jan./mar. 2013.

Facilitating factors for and barriers against nutritionists' practices relating to food and nutritional security were identified, from the perspective of coordinators of undergraduate nutrition courses in the municipality of São Paulo, Brazil. In this qualitative study, using collective subject discourse, coordinators were asked about factors favoring and limiting professional practice relating to food and nutritional security. Public policies and training were identified positively and negatively. The following central ideas were considered to be facilitators: "existence of public policies and programs" and "adequate training". The barriers identified were "insufficiency or non-application of these policies", "little possibility for nutritionists to act within the public sector" and "insufficient or inadequate training". It was concluded that coordinators placed value on the existence of policies, but the limitations of actions were clear. Although the training was considered adequate by some coordinators, it was criticized regarding its technical nature, fragmentation and disconnection between theory and practice.

Keywords: Food and nutritional security. Healthcare human resources. Higher education. Brazilian Health System. Nutritionist.
Identificaram-se fatores facilitadores e barreiras para a atuação do nutricionista em segurança alimentar e nutricional (SAN) na perspectiva de coordenadores de cursos de graduação em Nutrição do município de São Paulo, Brasil. Em estudo qualitativo, com uso do Discurso do Sujeito Coletivo, questionaram-se os coordenadores sobre aspectos favoráveis e limitadores da prática profissional em SAN. As políticas públicas e a formação foram apontadas positiva e negativamente. Como facilitadoras, verificaram-se as ideias centrais "existência de políticas e programas públicos" e "formação adequada"; como barreiras, a "insuficiência ou não-aplicação dessas políticas", "pouca possibilidade de atuação do nutricionista no setor público" e "formação insuficiente ou inadequada". Concluiu-se que coordenadores valorizam a existência de políticas públicas, porém é nítida a limitação de ações. A formação, considerada adequada por alguns, foi criticada quanto à tecnicidade, fragmentação e desarticulação entre teoria e prática.

Palavras-chave: Segurança alimentar e nutricional. Recursos humanos em saúde. Educação Superior. Sistema Único de Saúde. Nutricionista.
${ }^{1}$ Centro de Saúde Geraldo de Paula Souza, Faculdade de Saúde Pública, Universidade de São Paulo (USP). Av. Dr. Arnaldo, 925, São Paulo, SP, Brasil. 01.246-904. vivianevieira@usp.br ${ }^{2}$ Faculdade de Saúde Pública, USP. ${ }^{3}$ Departamento de Nutrição, Faculdade de Saúde Pública, USP. 


\section{Introdução}

O tema da Segurança Alimentar e Nutricional (SAN) emergiu no cenário político brasileiro a partir de 1999, com a divulgação da Política Nacional de Alimentação e Nutrição e, mais recentemente, com a Política Nacional de Segurança Alimentar e Nutricional (Brasil, 2010a). Tais políticas apontam para o planejamento, desenvolvimento e avaliação de ações de caráter holístico, intersetorial e contínuo, que extrapolam o campo do acesso ao alimento de qualidade, mas também se relacionam com promoção da saúde, sustentabilidade ambiental e econômica e soberania nacional (Brasil, 2006).

A implementação de ações e programas na perspectiva da SAN tem consolidado a importância do nutricionista, como profissional da saúde, em vários âmbitos. Segundo as Diretrizes Curriculares Nacionais para o Ensino Superior para o curso de Nutrição (Brasil, 2001), o nutricionista é um profissional da saúde com formação generalista, humanística e crítica, com atuação visando à segurança alimentar e à atenção dietética. Sua atuação deve estar pautada em princípios éticos, considerando aspectos socioeconômicos, políticos e culturais. Aspectos relacionados à sua formação serão fundamentais para garantir uma atuação competente.

O cenário da profissão indica a existência de 312 cursos e um aumento de 150\% no número de profissionais inscritos nos Conselhos, chegando a cinquenta mil nutricionistas (Brasil, 2011; Conselho Federal dos Nutricionistas, 2007). Esse aumento pela oferta de cursos de Nutrição está em consonância com a crescente demanda por profissionais da área da saúde (Haddad et al., 2010). Com o panorama nacional de políticas públicas que sustentam o tema de alimentação e nutrição, a demanda de profissionais para atuar nessa área também é elevada, constituindo-se em aspecto fundamental na implementação dos sistemas nacionais de saúde (Haddad et al., 2010). Tendo em vista tal contexto, o presente trabalho visa identificar fatores facilitadores e as barreiras para a atuação do nutricionista no âmbito da segurança alimentar e nutricional na perspectiva de coordenadores de cursos de Nutrição do município de São Paulo.

\section{Metodologia}

O presente estudo, de natureza qualitativa, foi desenvolvido com coordenadores pedagógicos dos cursos de graduação em Nutrição do município de São Paulo, de março a maio de 2010. A opção da seleção destes profissionais como informantes-chave prende-se ao fato de apresentarem responsabilidades definidas legalmente sobre assuntos ligados ao ensino, além de participarem diretamente da concepção dos currículos dos cursos, tal como apontam Secco e Pereira (2004).

Os cursos existentes no município foram identificados no website do Ministério da Educação e, em seguida, contataram-se as instituições para a confirmação da existência do curso. Das 18 instituições de Ensino Superior (IES) listadas, 14 tinham seus cursos ativos, distribuídos em seus diferentes campi, totalizando 24 unidades.

Os coordenadores das unidades foram contatados por vias telefônica e/ou eletrônica, sendo explicados a eles os objetivos do estudo e feito convite para a participação voluntária no mesmo. Atenderam, aos convites, 22 coordenadores responsáveis por cursos de 13 IES distintas.

A coleta de dados foi realizada por meio de entrevistas individuais utilizando roteiro que incluía informações pessoais sobre: sexo, tempo e local de formação universitária em Nutrição, titulação máxima, e tempo em que exerce a função de coordenador na instituição em que trabalha no presente momento. Além disso, os entrevistados foram questionados sobre sua percepção acerca dos aspectos favoráveis e das barreiras para a atuação do nutricionista no âmbito da segurança alimentar e nutricional.

Para a análise dos resultados, utilizou-se a técnica do Discurso do Sujeito Coletivo (DSC), que visa destacar uma dada representação social sob a forma de discurso que expressa o pensamento de uma coletividade, que vendo sendo utilizado pela comunidade científica em diferentes estudos (Kel, Shimizu, 2010; Paula, Palha, Protti, 2004). Para tanto, as respostas foram gravadas e transcritas integralmente e, em seguida, identificaram-se as expressões que representam uma ideia central (IC) e, posteriormente, foram reunidas de modo a constituir um DSC (Lefèvre, Lefèvre, 2006). 
Esse estudo foi realizado de acordo com as diretrizes e normas regulamentadoras da Resolução CNS 196/1996, e aprovado pelo Comitê de Ética em Pesquisa da Faculdade de Saúde Pública.

\section{Resultados e discussão}

Todos os entrevistados eram nutricionistas do sexo feminino. O tempo de formação universitária mostrou-se bastante variado, de oito a 32 anos, tendo a maioria se graduado no município de São Paulo, o que reflete maior conhecimento e envolvimento com questões sociais locais. Com relação à titulação, quase a totalidade apresentava, pelo menos, o título de Mestre, tal como indicado pelo Ministério da Educação (Brasil, 2010b).

Acerca do tempo de coordenação, grande parte ocupava o cargo há pouco tempo, indicando que essas profissionais recém-ingressadas são frutos do aumento do número de cursos no município ou, então, da rotatividade de profissionais no cargo: sete haviam ingressado a menos de um ano; sete tinham de um a cinco anos; três possuíam de seis a dez anos, e outras duas apresentavam mais de dez anos neste cargo. Não havia essa informação de três entrevistadas.

Na perspectiva destes coordenadores de curso, vários são os fatores que interferem na atuação do nutricionista no âmbito da SAN, tal como pode ser observado no Quadro 1, que aponta os facilitadores, e no Quadro 2, que indica as barreiras. É interessante perceber que exclusivamente questões relacionadas às políticas públicas e à formação do nutricionista são apontadas positiva e negativamente. Verificou-se que seis dos 22 coordenadores destacaram a situação política atual como aspecto importante que vem contribuindo para a atuação do nutricionista (IC1). A mesma quantidade de indivíduos elegeu a formação como um facilitador (IC2). Por outro lado, sete coordenadores apontaram a mesma formação como sendo uma barreira na atuação (IC9), e ocorreram duas ICs que remetem ao setor público, uma com oito coordenadores compartilhando da mesma ideia, intitulada "insuficiência ou não-aplicação das políticas públicas" (IC8), e outra com cinco, nomeada como "pouca possibilidade de atuação dos nutricionistas no setor público" (IC11).

É importante destacar o reconhecimento do panorama nacional de políticas públicas como aspecto favorável à atuação do nutricionista, tal como explicitado na IC1:

“[...] Hoje você tem documentos governamentais que tão dando respaldo pra gente ter um trabalho mais efetivo que eu acho que na minha formação, por exemplo, eu não tinha isso, né? Os programas todos que a gente vem observando, eles têm trazido um maior acesso, inclusive, do nutricionista, desde o Fome Zero, enfim, dos restaurantes populares [...] então, isso são oportunidades. (E também) a inserção do nutricionista na rede básica, que já tem em algumas unidades [...], a Política de Segurança Alimentar..."

Quadro 1. ICs sobre os facilitadores da atuação do nutricionista acerca da segurança alimentar e nutricional oriundas de depoimentos de coordenadores pedagógicos de cursos de graduação em nutrição do Município de São Paulo. São Paulo, 2010

\begin{tabular}{|l|l|}
\hline \multicolumn{1}{|c|}{ Ideia Central } & $\mathbf{n}$ \\
\hline IC1 - Existência de políticas e programas públicos & 6 \\
\hline IC2 - Formação adequada & 6 \\
\hline IC3 - Maior demanda para se ter o nutricionista & 6 \\
\hline IC4 - Atuação inerente à profissão & 5 \\
\hline IC5 - Habilidades pessoais & 2 \\
\hline IC6 - Não vejo facilitadores & 2 \\
\hline IC7 - Experiência profissional & 1 \\
\hline
\end{tabular}


ATUAÇÃO PROFISSIONAL NO ÂMBITO DA SEGURANÇA ALIMENTAR ...

Quadro 2. ICs sobre as barreiras para a atuação do nutricionista acerca da segurança alimentar e nutricional oriundas de depoimentos de coordenadores pedagógicos de cursos de graduação em nutrição do Município de São Paulo. São Paulo, 2010

\begin{tabular}{|l|c|}
\hline \multicolumn{1}{|c|}{ Ideia Central } & $\mathbf{n}$ \\
\hline IC8 - Insuficiência ou não-aplicação das políticas públicas & 8 \\
\hline IC9 - Formação insuficiente ou inadequada & 7 \\
\hline IC10 - Mercado de trabalho inadequado & 7 \\
\hline IC11 - Pouca possibilidade de atuação dos nutricionistas no setor público & 5 \\
\hline IC12 - Falta de conhecimento do nutricionista sobre a atuação em SAN & 4 \\
\hline IC13 - Desvalorização da área por parte do nutricionista & 2 \\
\hline IC14 - Pouca informação da sociedade & 2 \\
\hline IC15 - Nenhuma & 1 \\
\hline
\end{tabular}

Mesmo que a Política Nacional de Segurança Alimentar e Nutricional, que regulamenta a Lei Orgânica da Segurança Alimentar e Nutricional (Brasil, 2010a), tenha sido instituída após a realização da coleta de dados para a presente pesquisa, o cenário voltado ao tema vem beneficiando a atuação do nutricionista desde 1999, com a implementação da Política Nacional de Alimentação e Nutrição. Essa política apresenta, dentre suas diretrizes, a cooperação e a articulação para a SAN (Brasil, 2012). A SAN foi reafirmada em 2006, com a Política Nacional de Promoção da Saúde, cujo documento descreve, dentre suas ações específicas, a alimentação saudável em prol do DHAA (Brasil, 2006); está contida na Lei 11.947, que dispõe sobre o atendimento da alimentação escolar (Brasil, 2009a) e no âmbito das ações de alimentação e nutrição na atenção básica (Brasil, 2009b). Apesar de todos os documentos respaldarem-se na intersetorialidade, é inegável que o nutricionista consiste em profissional com responsabilidade direta de atuação nesse cenário.

Ao longo das últimas décadas, a evolução das políticas na área de alimentação e de nutrição vem impactando na atuação do nutricionista (Vasconcelos, 2002). Políticas públicas relacionadas ao tema da SAN estão diretamente ligadas a características sociais do país, que, por sua vez, oferecem ao profissional possibilidades de desenvolvimento de trabalho na área da gestão, da educação e no terceiro setor; potencializa o mercado de trabalho do profissional, ampliando as possibilidades da inserção, no mercado de trabalho, da mão de obra existente, tal como aponta a IC3:

“É, eu acho que [...] um pouco mais de compreensão das pessoas [...]. Porque alimentação é um tema que, ultimamente, está sempre em pauta, sempre na mídia... coisa que há pouco tempo atrás a gente não tinha nada. Eu acho que é até uma pressão social, né? A prevalência de obesidade aumentando, prevalência de diabetes, de câncer, de doenças cardiovasculares. E quanto pior esse cenário vai ser pintado, isso vai ser um facilitador para que a atuação do nutricionista seja valorizada... Então, eu acho que, o que ajuda muito a atuação do profissional são as pesquisas que têm demonstrado cada vez mais a importância do profissional na educação, na prevenção de ter uma alimentação adequada".

Ademais, o padrão de morbimortalidade mundial permite apontar o estilo de vida moderno e ocidental como fator importante na etiologia de grande parte das doenças da atualidade. Estudos epidemiológicos evidenciam: elevada frequência de fatores de risco como tabagismo, consumo excessivo de bebidas alcoólicas, hábitos alimentares inadequados, sedentarismo e estresse, que impulsionam a crescente epidemia de obesidade, hipertensão arterial, diabetes mellitus tipo 2 e dislipidemias (Brasil, 2012; Vieira, Reis, 2010; Organização Mundial da Saúde, 2004). Esse cenário vem demandando a atuação de profissionais da área da saúde. No campo da Nutrição, a graduação, criada 
em 1939, vem crescendo de modo representativo, sobretudo no início do século XXI. De 2000 a 2007, houve aumento anual de $11,7 \%$ nas taxas médias de inscrições de nutricionistas no Conselho regulamentador federal (CFN, 2007), indicando a necessidade social da existência desse profissional e direcionando, assim, sua formação, tendo em vista que os cursos tendem a se adaptar às necessidades da população e do mercado.

Com relação à insuficiência ou não-aplicação das políticas públicas (IC8), o primeiro aspecto (insuficiência) é incoerente com o cenário nacional, porém é importante destacar a dificuldade para a sua concretização. Recine e Vasconcellos (2011) indicam que as características de implementação de uma política revelam seu verdadeiro significado, e, não diferentemente, as de alimentação deparam com desafios para profissionais, pesquisadores e gestores, sendo a organização do processo de trabalho um aspecto a ser superado. Situação que exemplifica tal ideia é a limitação de implantação do Sistema de Vigilância Alimentar e Nutricional (Sisvan) no estado de São Paulo, acontecendo parcialmente nos municípios (Venâncio et al., 2007). Esta ideia surge no trecho do seguinte DSC:

\footnotetext{
"O que dificulta são as poucas ou a falta de políticas públicas pra que nós tenhamos programas que visam a SAN... Eu acho que o problema tá lá na ponta do iceberg, nos nossos governantes, né? Eu mesma trabalhei na parte da prefeitura, e a gente tinha aquele projeto de educação nutricional e que de repente não era mais favorável à política e simplesmente cancelaram $[\ldots]^{\prime \prime}$.
}

A partir da análise das Diretrizes Curriculares Nacionais (Brasil, 2001), na qual a SAN é vinculada à atuação profissional, independentemente do cenário, público ou privado, atividades em prol do direito humano à alimentação adequada (DHAA) deveriam ser contempladas em sua prática. Foi nítido, porém, o discurso de que ações na SAN são desenvolvidas por profissionais ligados ao governo (IC8), mostrando que talvez esse conceito ainda não esteja efetivamente traduzido em possibilidades de atuação na área da saúde. Isso vai de encontro aos achados de Vieira e Cervato-Mancuso (2009), que mostraram que, dentre 24 nutricionistas atuantes na área de saúde coletiva, somente quatro relacionaram a SAN com direito humano. Ou seja, os profissionais que estariam ligados ao governo ainda associam SAN ao alimento seguro.

A percepção da influência negativa com relação ao cenário de políticas públicas constituiu aspecto identificado na fala de parte dos coordenadores, sinalizando para a confusão entre o conceito que remete à organização do Estado para o estabelecimento de princípios e medidas para a resolução de problemas sociais (Benevides, Passos, 2005), e aquele relativo às barreiras ligadas com a governabilidade ou gestão dessas ações. Relevante também é o processo de concepção de tais políticas, especialmente aquelas relacionadas com a SAN, representativas de conquistas de grupos sociais específicos, a partir de cenários da história nacional, que refletem o processo de mudança dos paradigmas de saúde, culminando na proposição da Política Nacional de Segurança Alimentar e Nutricional (Brasil, 2010a).

Além dos aspectos já elucidados, o mercado de trabalho, sem se especificar se privado ou público, também é apontado como barreira existente para a atuação (IC10). As más condições de trabalho na área também foram apontadas como uma barreira para a atuação, com ênfase na questão salarial. A remuneração salarial tem sido tema de debates entre as entidades de classe. Em 2005, o salário médio de um nutricionista atuante na área da saúde coletiva era de 4,9 salários-mínimos, valor inferior à área de ensino, indústria e nutrição clínica (CNF, 2006). Tal aspecto, entretanto, apresenta-se com possibilidade de intervenção pública limitada, devendo, portanto, ser discutido em conselhos, sindicatos e associações profissionais, a fim de regulamentar as diversas áreas de atuação profissional. O DSC que reflete a ideia relativa à inadequação do mercado de trabalho encontra-se a seguir:

“Eu acho que a gente tem formação pra isso, mas não tem campo pra atuar. Ele é um profissional ainda que ele não tem muito espaço em algumas áreas. Os salários ainda são mais baixos do que de outras áreas. (E) o que dificulta é a visão dos nossos empregadores... é a visão de troca financeira, de lucro e não tanto a preocupação com relação à saúde". 
ATUAÇÃO PROFISSIONAL NO ÂMBITO DA SEGURANÇA ALIMENTAR ...

A limitada inserção do nutricionista no setor público também consistiu em barreira vislumbrada pelos coordenadores (IC11):

"Olha, o que atrapalharia, talvez, seria a abertura pro nutricionista poder estar desenvolvendo essas ações, né? Se nós tivéssemos, de fato, esse profissional atuando na saúde pública, na questão preventiva, eu acho que esse seria um grande aliado ao nosso favor. Porque tem profissional, a gente tem formado gente pra isso, mas não tem a vaga".

O nutricionista iniciou sua participação no setor público mais tardiamente e em menores proporções, comparativamente a outras áreas, como medicina e enfermagem. Em 2006, o Conselho Federal de Nutricionistas verificou que 8,1\% encontravam-se atuando na área de saúde coletiva, como na atenção básica em saúde, vigilância sanitária e políticas e programas institucionais. É importante destacar, porém, que o cenário vem se alterando recentemente. No município de São Paulo, existem 123 nutricionistas atuantes em unidades básicas de saúde (UBS), sendo funcionários diretamente ligados à prefeitura e atuantes nesses locais (Cervato-Mancuso et al., 2012). Em 2008, foram criados os Núcleos de Apoio à Saúde da Família (Nasf), existindo a possibilidade da inserção do nutricionista nas equipes. Os Nasfs são geridos por empresas públicas ou privadas: em 2009, as informações eram de que existiam 51 nutricionistas contratados, com perspectiva de outras vagas a serem ocupadas (Brasil, 2009c). Dessa forma, apesar de nitidamente o número de nutricionistas ser aquém do ideal para a execução das atividades pertinentes ao profissional, o campo de atuação no setor público está sendo estabelecido.

A formação adequada (IC2) constituiu outro aspecto relevante para a atuação do nutricionista, destacado pelos coordenadores.

"A gente tem disciplinas que trabalham isso, como as Políticas Públicas, a própria Saúde Pública Aplicada à Nutrição, a Saúde Pública, a Epidemiologia, o Saneamento, a Avaliação Nutricional, Educação Nutricional, que a gente acaba trabalhando essa teoria das competências e habilidades a serem desenvolvidas no aluno, né?".

Essa questão está em consonânca com as Diretrizes Curriculares Nacionais (Brasil, 2001), que representam uma conquista ao considerar que o profissional deve apresentar formação humanística e crítica, voltada para a atenção dietética e para a SAN. Para tanto, os cursos de graduação devem oferecer oportunidades para o desenvolvimento de competências, tais como: atuação em políticas e programas de diversas áreas e na formulação e execução de programas de educação nutricional de vigilância nutricional, indicando a extrapolação do desenvolvimento de ações de prescrição e orientação dietética individual. É importante destacar que não somente as determinações da área da saúde, mas também as educacionais, são de responsabilidade do Estado ao formular políticas públicas relativas ao Ensino Superior. Assim, mudanças existentes nos currículos dos cursos são resultantes, dentre outros fatores, de iniciativas públicas.

De modo complementar à formação profissional, outro aspecto, nomeado "atuação inerente à profissão" (IC4), evidencia que, por conta de características próprias do profissional, diferentemente de outros, o nutricionista apresenta facilidade para atuar em relação à SAN:

"E o nutricionista é um profissional de referência pra discutir questões de alimentação, porque o alimento é nosso ambiente de trabalho [...] A criatividade e as estratégias são inerentes da profissão, né? Eu acredito que nós temos muito mais instrumentos, ferramentas pra conseguir, então a gente tem toda a parte metodológica, [...] fornecendo conhecimento pro seu público em geral, seja de qual área for".

A atuação acerca da alimentação adequada confere a esse profissional uma condição peculiar na área da saúde: o perfil de educador para a proposição de mudanças de comportamento perante a sociedade, tal como analisam Banduk, Ruiz-Moreno e Batista (2009), em pesquisa que também envolveu 
coordenadores do curso de Nutrição. Dessa forma, ele é capaz de traduzir a ciência da nutrição em informações práticas que subsidiem melhores escolhas alimentares pela população, além de ter habilidades para trabalhar junto às comunidades, visando identificar suas necessidades e facilitar a construção de saberes em prol da defesa da saúde e da ação social.

Ademais, dentre a equipe de saúde, o nutricionista é aquele com habilidades e competências, conferidas pela regulamentação profissão, para aconselhar sobre dieta, alimentação e nutrição, apresentando distintas possibilidades de atuação profissional, como em serviços de saúde, atendimento domiciliar, hospitais, unidades de alimentação, esporte e marketing. Tendo em vista a relação entre alimentação e saúde, e que o ato de se alimentar é fundamental para a sobrevivência, além de estar arraigado de valores sociais, históricos, econômicos e culturais, o nutricionista adquire papel efetivo na promoção da saúde (Dietitians of Canada, 2001).

A formação também foi considerada insuficiente por parte dos coordenadores (IC9):

\begin{abstract}
"Eu acho que há uma preocupação maior com outras áreas de atuação em administração, em clínica, mas não com a segurança nutricional como um todo. Se a gente pensar só na segurança, a questão do controle higiênico-sanitário, eu acho que a gente dá mais conta dessa formação. Até muito recentemente, os cursos valorizavam demais o biológico em detrimento do social e o nutricionista saía com uma visão de que ele era o curador [...] e não aquele profissional que promove, que educa, que incentiva uma alimentação mais saudável. Eu não acho também que o enfoque é SAN... Isso é ministrado de uma forma fragmentada em algumas disciplinas, porque eu acho que não é muito valorizado, né?".
\end{abstract}

De modo geral, as profissões relacionadas à saúde vêm sendo alvo de discussão, tendo em vista a necessidade de reorientação das práticas desses profissionais. Junqueira et al. (2010) apontam para a importância da formação de recursos humanos com características de autonomia e para a transformação da realidade. Já Feuerwerker (2001) defende que a mudança na graduação, a concepção ampliada de saúde, a integralidade, as práticas inovadoras e a rede de cuidados se tornarão realidade, efetivamente, dentro das escolas se forem objetivos a serem atingidos em todos os serviços de saúde, e não somente na rede pública, que é a tradução mais frequente de SUS, indicando que a atuação do profissional necessita se estender às diversas áreas que competem a ele.

A percepção superficial dos nutricionistas sobre as possibilidades de atuação na SAN, associadas às críticas realizadas pelos coordenadores sobre problemas na formação desse profissional, sustentam indícios de que os projetos político-pedagógicos (PPP) dos cursos ainda não promovem a formação nessa área. As atuais Diretrizes Curriculares para o curso de Nutrição apontam para competências, como o reconhecimento da saúde como direito, com atuação integral acerca dela, enquanto Soares, Aguiar (2011) mostra que os projetos não priorizam a discussão sobre os valores humanos, éticos e culturais e a compreensão da realidade a partir de seu contexto histórico, econômico e político.

Apesar de Banduk, Ruiz-Moreno e Batista (2009) enfatizarem que coordenadores do curso de Nutrição apontam para a necessidade de formação comprometida com os processos de transformação social, extrapolando as habilidades técnicas, fica evidente a dificuldade para que isso aconteça, inclusive no âmbito da SAN. Isso é ratificado na pesquisa de Soares e Aguiar (2011) com docentes do curso de Nutrição, ao considerar que as participantes da pesquisa consideraram a graduação frágil, técnica e teórica, e que os PPPs não estariam promovendo a formação na SAN prevista no perfil do egresso.

A reflexão quanto à formação na graduação, porém, não deve estar limitada somente à adequação das disciplinas que constituem o currículo. Tendo em vista que SAN perpassa por diversas áreas, entende-se que a abordagem desse tema na graduação deveria ocorrer de modo transversal; e metodologias de ensino e de avaliação em classe e incentivo a atividades extraclasse contribuem para essa formação, por desenvolverem habilidades de comunicação, liderança, tomada de decisões, ética e trabalho em equipe.

Distintos aspectos considerados como desfavoráveis à formação também vêm sendo discutidos. Costa (2002) elege como desafios: a reduzida carga horária para atividades de extensão e de pesquisa e o excesso de tempo destinado a temas do currículo do ciclo básico, e a desarticulação entre teoria e 
ATUAÇÃO PROFISSIONAL NO ÂMBITO DA SEGURANÇA ALIMENTAR ...

prática e entre os conteúdos teóricos entre si. Experiências que integram teoria e prática são relevantes, segundo Pedroso e Cunha (2008), por contribuírem para o estabelecimento de relações entre as vivências de estágios e os conhecimentos já presentes na estrutura cognitiva do aluno, propiciando que este seja protagonista na construção de seu conhecimento.

A própria formação política constitui aspecto relevante a ser considerado para a atuação do nutricionista, tendo em vista que este deve adquirir habilidades ao longo da graduação para atuar em políticas e programas distintos (Brasil, 2001). Mesmo frente às críticas existentes sobre a formação do nutricionista, por ter enfoque predominante em ciências biológicas em detrimento do campo políticosocial, Padua e Boog (2008) destaca a necessidade de os cursos extrapolarem as discussões ideológicas para contribuírem para a reflexão crítica sobre a realidade social e a prática profissional a partir desta perspectiva.

A formação e o preparo dos docentes, apesar de não terem sido elucidados pelos entrevistados, torna-se um tema questionável para Amorim, Moreira e Carraro (2001) e para Costa (2009). É crescente a ênfase que vem sendo dada à necessidade de se gerar um profissional apto a contribuir com a sociedade além das aptidões técnicas inerentes à profissão, mas também nos campos político e social. Entretanto, professores tendem a reproduzir práticas de ensino fundadas na transmissão de conteúdos, o que pode estar relacionado com a própria formação do docente, dado que não há ênfase na área pedagógica para aquele que busca assumir essa função. Além disso, a desvalorização da carreira é outro aspecto que influencia a prática em sala de aula, dado que muitas instituições valorizam a pesquisa científica em detrimento da formação na graduação (Costa, 2002). As condições de muitas salas de aula, com número elevado de alunos e carga horária de trabalho elevada, também limitam o aprofundamento do processo de ensino entre aluno e professor.

Percepções contrastantes sobre os mesmos fatores relacionados à atuação do nutricionista na SAN apontam para divergências em relação às políticas públicas na área da alimentação e nutrição e à formação que é oferecida ao estudante de Nutrição. Por outro lado, a menção de ambos os aspectos de modo tão evidente indica a importância da sua consideração para a discussão da atuação em SAN.

Em síntese, a atuação na SAN vem sendo discutida com ênfase crescente no Brasil, levando, consequentemente, à reflexão sobre a profissão do nutricionista. O presente trabalho se propôs a elucidar aspectos a serem considerados de modo a contribuir para a incorporação da SAN em suas ações, sendo que emergiram o papel da formação e a complexidade da organização política para abarcar essa atuação. Tendo em vista que o objetivo inicial não vislumbrava a dualidade, posteriormente encontrada entre a formação e as políticas públicas, não foi possível aprofundar a discussão desses temas com os coordenadores investigados. Em contrapartida, as reflexões realizadas neste artigo permitem solidificar as contribuições existentes e perspectivar as lacunas reais para a atuação do nutricionista.

Mesmo com a distância ainda existente entre a formação e o poder público, iniciativas têm sido promovidas de modo a superar tal condição. O Programa Nacional de Reorientação da Formação Profissional em Saúde (Pró-Saúde), criado em 2007, visa promover a transformação do ensino em saúde no país, integrando-o à prestação de serviços à população (Brasil, 2007). Em consonância com o PróSaúde, o Programa de Educação pelo Trabalho para a Saúde (PET-Saúde) viabiliza programas de aperfeiçoamento e especialização em serviço dos profissionais da saúde e de iniciação ao trabalho aos estudantes da área, de acordo com as necessidades do Sistema Único de Saúde (Brasil, 2008). Assim, o apoio que vem sendo dado para que alguns cursos de Nutrição no país reestruturem-se - promovendo a incorporação de práticas de atenção básica de saúde na formação dos alunos e o estabelecimento de canais que, mutuamente, incentivem a prática discente e a educação continuada de profissionais da saúde - vem ao encontro de uma das diretrizes da Política Nacional de Alimentação e Nutrição (Brasil, 2012), que estabelece a qualificação da força de trabalho, com foco no Sistema Único de Saúde, visando ao acesso universal ao alimento. 


\section{Conclusões}

Com a ampliação do conceito da SAN no cenário nacional, relacionando-o com a promoção da saúde e a questões de caráter intersetorial, a atuação do nutricionista necessita estar em consonância com as atuais políticas públicas e com as diretrizes que norteiam a formação deste profissional.

Foram distintos os aspectos destacados como barreiras e facilitadores para a atuação do nutricionista visando à SAN na perspectiva dos coordenadores de curso. O reconhecimento tanto das políticas públicas voltadas ao tema quanto da formação profissional está presente nas falas dos coordenadores, porém com percepções contraditórias. Foi nítida a consideração da limitação de ações na instância pública como uma barreira importante da atuação do nutricionista, sinalizando que a instituição parece não reconhecer que o nutricionista deve se apropriar da SAN em qualquer área de atuação. Mesmo existindo políticas relacionadas ao tema, os discursos mostraram que elas não são tidas como adequadas para a atuação vislumbrada pelos coordenadores, evidenciando incompatibilidade entre a expectativa que se constrói no egresso e as necessidades populacionais apontadas pelo Estado.

Por outro lado, a formação proporcionada no Ensino Superior, apesar de ter sido destacada como adequada por alguns, ainda é considerada focada em competências técnicas em detrimento das humanísticas, fragmentada e desarticulada quanto às atividades teóricas e práticas, desfavorecendo a atuação do futuro profissional visando ao direito humano à alimentação adequada.

Mesmo que em situação de conflito, foi evidente a responsabilidade conferida, pelos coordenadores, aos cursos de graduação e ao Estado para contribuírem para a atuação do nutricionista em SAN. Por outro lado, é importante destacar que estes dois aspectos encontram-se articulados, dado que a formação conferida pelo curso de graduação pode promover uma atuação profissional inserida em contexto políticos, enquanto o Estado pode direcionar o Ensino Superior por meio de políticas públicas.

Conclusivamente, a politização do nutricionista consiste em estratégia fundamental para contribuir para a sua atuação na perspectiva da SAN, conferindo a ele visão crítica e ampliada sobre alimentação e nutrição. Ademais, possibilita-se, assim, que este ocupe espaços que vão além da atuação direta com a população, contribuindo que se aproprie de áreas de gestão e administração de políticas e programas em distintos setores.

\section{Colaboradores}

Viviane Laudelino Vieira participou da concepção e desenvolvimento da pesquisa, análise dos resultados e redação do artigo; Natália Utikava participou do desenvolvimento da pesquisa, análise dos dados e revisão do artigo; Ana Maria Cervato-Mancuso participou da orientação de todo o processo que envolveu a realização da pesquisa e consequente redação do artigo.

\section{Agradecimentos}

Os autores agradecem ao grupo de pesquisa, credenciado ao CNPq, "Segurança alimentar e nutricional: formação e atuação profissional", pelo apoio, colaboração e parceria. 


\section{Referências}

AMORIM, S.T.S.P.; MOREIRA, H.; CARRARO, T.E. A formação de pediatras e nutricionistas: a dimensão humana. Rev. Nutr., v.14, n.2, p.111-8, 2001. doi: 10.1590/S1415-52732001000200004.

BANDUK, M.L.S.; RUIZ-MORENO, L.; BATISTA, N.A. A construção da identidade profissional na graduação do nutricionista. Interface - Comunic., Saude, Educ., v.13, n.28, p.111-20, 2009. doi: 10.1590/S1414-32832009000100010.

BENEVIDES, R.; PASSOS, E. A humanização como dimensão pública das políticas de saúde. Cienc. Saude Colet., v.10, n.3, p.561-71, 2005. doi: 10.1590/S141432832005000200014.

BRASIL. Parecer CNE/CES no 1.133, de 7 de agosto de 2001. Diretrizes Curriculares Nacionais dos Cursos de Graduação em Enfermagem, Medicina e Nutrição. Brasília: Ministério da Educação, 2001.

Ministério da Educação. Instituiçõos de ensino superior e cursos cadastrados: Nutrição. 2011. Disponível em: <http://emec.mec.gov.br>. Acesso em: 10 dez. 2012.

Ministério da Saúde. Política Nacional de Alimentação e Nutrição. Brasília: Ministério da Saúde, 2012.

Decreto no 7.272, de 25 de agosto de 2010. Regulamenta a Lei no 11.346, de 15 de setembro de 2006, que cria o Sistema Nacional de Segurança Alimentar e Nutricional - SISAN, com vistas a assegurar o direito humano à alimentação adequada, institui a Política Nacional de Segurança Alimentar e Nutricional - PNSAN, estabelece os parâmetros para a elaboração do Plano Nacional de Segurança Alimentar e Nutricional e dá outras providências. 2010a. Disponível em: <http://www.mds.gov.br/ sobreoministerio/legislacao/segurancaalimentar/decretos/2010/Decreto\% 207.2722010.pdf>. Acesso em: 10 dez. 2012.

Lei das diretrizes e bases da educação nacional. 5.ed. Brasília: Ministério da Saúde, 2010b. Disponível em: <http://www.planalto.gov.br/ccivil_03/leis/ L9394.htm>. Acesso em: 10 dez. 2012.

Lei $n^{\circ} 11.947$, de 16 de junho de 2009. Dispõe sobre o atendimento da alimentação escolar e do Programa Dinheiro Direto na Escola aos alunos da educação básica; altera as Leis 10.880, de 9 de junho de 2004, 11.273, de 6 de fevereiro de 2006, 11.507, de 20 de julho de 2007; revoga dispositivos da Medida Provisória 2.178-36, de 24 de agosto de 2001, e a Lei 8.913, de 12 de julho de 1994; e dá outras providências. Brasília: Ministério da Saúde, 2009a. Disponível em: <http:// www.planalto.gov.br/ccivil_03/_ato2007-2010/2009/lei/l11947.htm>. Acesso em: 10 dez. 2012.

Matriz de ações de alimentação e nutrição na atenção básica de saúde. Brasília: Ministério da Saúde, 2009b. Disponível em: < http://189.28.128.100/ nutricao/docs/geral/matriz_acoes_an_abs_2009.pdf>. Acesso em: 10 dez. 2012.

Cadastro Nacional de Estabelecimentos de Saúde. Brasília: Ministério da Saúde, 2009c. Disponível em: <http://cnes.datasus.gov.br/Lista_Es_Municipio.asp? VEstado $=35 \&$ VCodMunicipio $=355030 \&$ NomeEstado $=$ SAO $\%$ 20̈PAULO $>$. Acesso em: 10 dez. 2012.

Portaria interministerial no 1.802, de 26 de agosto de 2008. Institui o Programa de Educação pelo Trabalho para a Saúde - PET-Saúde. Diário Oficial da União, Brasília, DF, 27 ago. 2008 . Seção 1, p.37.

Programa Nacional de Reorientação da Formação Profissional em Saúde.

Pró-Saúde. Objetivos, implementação e desenvolvimento social, 2007. Brasília, Disponível em: <http://www.prosaude.org/rel/pro_saude1.pdf>. Acesso em: 10 dez. 2012. 
VIEIRA, V.L.; UTIKAVA, N.; CERVATO-MANCUSO, A.M.

BRASIL. Política Nacional de Promoção da Saúde. Brasília: Ministério da Saúde, 2006.

CERVATO-MANCUSO, A.M. et al. A atuação do nutricionista na Atenção Básica à Saúde em um grande centro urbano. Cienc. Saude Colet., v.17, n.12, p.3289-300, 2012. doi: 10.1590/S1413-81232012001200014.

CONSELHO FEDERAL DOS NUTRICIONISTAS. O papel do nutricionista na atenção primária à saúde. Brasília: CFN, 2008.

A história do nutricionista no Brasil. BRASÍLIA: CNF, 2007. Disponível em: <http://www.cfn.org.br/eficiente/repositorio/Comunicacao/Material_institucional/ 160.pdf>. Acesso em: 10 dez. 2012.

Inserção profissional dos nutricionistas no Brasil. Brasília: CFN, 2006.

COSTA, N.M.S.C. Formação pedagógica dos professores de nutrição: uma omissão consentida? Rev. Nutr., v.22, n.1, p.97-104, 2009. doi: 10.1590/S141552732009000100009.

COSTA, N.S.C. A formação do nutricionista: educação e contradição. 2.ed. Goiânia: UFG, 2002.

DIETITIANS OF CANADA. The role of the registered dietitian in primary health care: a national perspective. Toronto: CDHC, 2001.

FEUERWERKER, L.C.M. Estratégias para a mudança da formação dos profissionais de saúde. Cad. CE, v.3, n.4, p.11-23, 2001.

HADDAD, A.E. et al. Formação de profissionais de saúde no Brasil: uma análise no período de 1991 a 2008. Rev. Saude Publica, v.44, n.3, p.383-93, 2010. doi: 10.1590/ S0034-89102010005000015.

JUNQUEIRA, T.S. et al. As relações laborais no âmbito da municipalização da gestão em saúde e os dilemas de relação expansão/precarização no trabalho no contexto do SUS. Cad. Saude Publica, v.26, n.5, p.918-28, 2010. doi: 10.1590/S0102$311 \times 2010000500014$.

KELL, M.C.G.; SHIMIZU, H.E. Existe trabalho em equipe no Programa Saúde da Família? Cienc. Saude Colet., v.15, supl.1, p.1533-41, 2010. doi: 10.1590/S141381232010000700065.

LEFÈVRE, F.; LEFÈVRE, A.M.C. O sujeito coletivo que fala. Interface - Comunic., Saude, Educ., v.10, n.20, p.517-24, 2006. doi: 10.1590/S1414-32832006000200017.

MARTINS, A.R. et al. Práticas dos trabalhadores de saúde na comunidade nos modelos de atenção básica do Sul e Nordeste do Brasil. Cad. Saude Publica, v.26, n.12, p.2279-95, 2010. doi: 10.1590/S0102-311X2010001200007.

MOSCOVICl, S. Representações sociais: investigações em psicologia social. Rio de Janeiro: Vozes, 2003.

ORGANIZAÇÃO MUNDIAL DE SAÚDE. Global strategy on diet, physical activity and health. Geneva: OMS, 2004.

PADUA, J.G.; BOOG, M.C.F. Avaliação da inserção do nutricionista na Rede Básica de Saúde dos municípios da Região Metropolitana de Campinas. Rev. Nutr., v.19, n.4, p.413-24, 2006. doi: 10.1590/S1415-52732006000400001.

PAULA, K.A.; PALHA, P.F.; PROTTI, S.T. Intersetorialidade: uma vivência prática ou um desafio a ser conquistado? O Discurso do Sujeito Coletivo dos enfermeiros nos núcleos de Saúde da Família do Distrito Oeste - Ribeirão Preto. Interface - Comunic., Saude, Educ., v.8, n.15, p.331-48, 2004. doi: 10.1590/S1414-32832004000200011.

PEDROSO, M.B.; CUNHA, M.I. Vivendo a inovação: as experiências no curso de nutrição. Interface - Comunic., Saude, Educ., v.12, n.24, p.141-52, 2008. doi: 10.1590/S1414-32832008000100011. 
RECINE, E.; VASCONCELLOS, A.B. Políticas nacionais e o campo da Alimentação e Nutrição em Saúde Coletiva: cenário atual. Cienc. Saude Colet., v.16, n.1, p.73-9, 2011. doi: 10.1590/S1413-81232011000100011.

SECCO, L.G.; PEREIRA, M.L.T. Concepções de qualidade de ensino dos coordenadores de graduação: uma análise dos cursos de odontologia do Estado de São Paulo.

Interface - Comunic., Saude, Educ., v.8, n.15, p.313-30, 2004. doi: 10.1590/S141432832004000200010 .

SOARES, N.T.; AGUIAR, A.C. Diretrizes curriculares nacionais para os cursos de nutrição: avanços, lacunas, ambiguidades e perspectivas. Rev. Nutr., v.23, n.5, p.895-905, 2011. doi: 10.1590/S1415-52732010000500019.

VASCONCELOS, F.A.G. O nutricionista no Brasil: uma análise histórica. Rev. Nutr., v.15, n.2, p.127-38, 2002. doi: 10.1590/S1415-52732002000200001.

VENÂNCIO, S.I. et al. Sistema de vigilância alimentar e nutricional do Estado de São Paulo, Brasil: experiência da implementação e avaliação do estado nutricional de crianças. Rev. Bras. Saude Mater. Infant., v.7, n.2, p.213-20, 2007. doi: 10.1590/ S1519-38292007000200012.

VIEIRA, V.L.; CERVATO-MANCUSO, A.M. Percepções acerca da segurança alimentar e nutricional entre nutricionistas do município de São Paulo, Brasil. In: CONGRESO LATINOAMERICANO DE NUTRICIÓN, 15., 2010, Santiago. Anais... Santiago, 2009. 1 cd-rom.

VIEIRA, V.L.; REIS, L.C. The future of human nutrition. In: GUINÉ, R.P. (Ed.). Food, diet and health: past, present and future tendencies. New York: Nova Science, 2009. p.403-41.

VIEIRA, V.L.; UTIKAVA, N.; CERVATO-MANCUSO, A.M. Las actividades profesionales en el ámbito de la seguridad alimentaria y nutricional en la perspectiva de los coordinadores de cursos de graduación en Nutrición. Interface - Comunic., Saude, Educ., v.17, n.44, p.159-70, jan./mar. 2013.

Se identifican los facilitadores y las barreras para el trabajo del nutricionista relacionados a la seguridad alimentaria y nutricional en la perspectiva de los coordinadores de cursos de Nutrición en São Paulo, Brasil, en un estudio cualitativo por medio de Discurso del Sujeto Colectivo. La política pública y la capacitación fueron mencionados tanto positiva como negativamente. Como facilitadores, fueran identificadas las ideas "existencia de políticas y programas públicos" y "formación adecuada" y como barrera, "la insuficiencia o no aplicación de tales políticas", "pocas posibilidades de acción de nutricionista en el sector público" y "formación insuficiente o inadecuada". Los coordinadores indican las políticas como importantes pero las acciones públicas son restrictas. La formación, aunque considerada adecuada por algunos, se ha criticado en cuanto a la complejidad técnica, la fragmentación y la desconexión entre la teoría y la práctica.

Palabras clave: Seguridad alimentaria. Recursos Humanos en Salud. Educación Superior. Sistema Único de Salud. Nutricionista. 